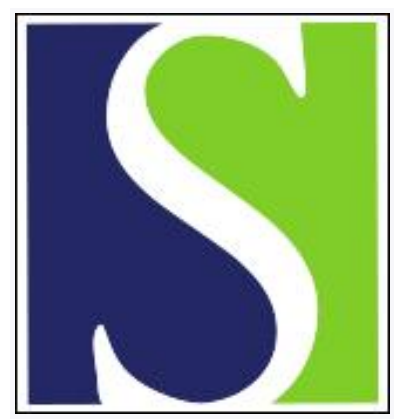

Scand J Work Environ Health 2002;28(1):18-24

https://doi.org/10.5271/sjweh.642

Issue date: Feb 2002

Effects of ergonomic intervention in work with video display units

by Ketola R, Toivonen R, Häkkänen M, Luukkonen R, Takala E-P, Viikari-Juntura E; the Expert Group of Ergonomics

Affiliation: Finnish Institute of Occupational Health, Topeliuksenkatu 41 a A, FI-002500 Helsinki, Finland. ritva.ketola@ttl.fi

Refers to the following text of the Journal: 1999;25(3):255-263

The following articles refer to this text: 2002;28(4):211-213;

2003;29(5):396-405; 2004;30(5):390-398; 2011;37(5):363-375; 2011;37(5):383-393

Key terms: diary of discomfort; ergonomic intervention; musculoskeletal discomfort; musculoskeletal pain; musculoskeletal strain; neck pain; participatory ergonomics; randomized controlled trial; shoulder pain; video display unit; workload

This article in PubMed: www.ncbi.nlm.nih.gov/pubmed/11871848

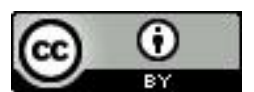




\title{
Effects of ergonomic intervention in work with video display units
}

\author{
by Ritva Ketola, MSc, ${ }^{1}$ Risto Toivonen, MSc(Tech), ${ }^{1}$ Marketta Häkkänen, MSc, ${ }^{1}$ Ritva Luukkonen, PhD, ${ }^{1}$ \\ Esa-Pekka Takala, DMedSci, ${ }^{1}$ Eira Viikari-Juntura, DMedSci, ${ }^{1}$ the Expert Group in Ergonomics ${ }^{2}$
}

Ketola R, Toivonen R, Häkkänen M, Luukkonen R, Takala E-P, Viikari-Juntura E, the Expert Group in Ergonomics. Effects of ergonomic intervention in work with video display units. Scand J Work Environ Health 2002;28(1):1824.

Objectives This study evaluated the effect of an intensive ergonomic approach and education on workstation changes and musculoskeletal disorders among workers who used a video display unit (VDU).

Methods A randomized controlled design was used. The subjects ( $\mathrm{N}=124)$ were allocated into three groups (intensive ergonomics, ergonomic education, reference) using stratified random sampling. The evaluation involved questionnaires, a diary of discomfort, measurements of workload, and an ergonomic rating of the workstations. The assessments were made 2 weeks before the intervention and after 2 and 10 months of followup.

Results The intensive and training groups showed less musculoskeletal discomfort than the reference group after 2 months of follow-up. Positive effects on discomfort were seen primarily for the shoulder, neck, and upper back areas. No significant differences were found for the strain levels or prevalence of pain. After the intervention the ergonomic level was distinctly higher in the intensive ergonomic group than in the education or reference group.

Conclusions Both the intensive ergonomics approach and education in ergonomics help reduce discomfort in VDU work. In attempts to improve the physical ergonomics of VDU workstations, the best result will be achieved with cooperative planning in which both workers and practitioners are actively involved.

Key terms diary of discomfort, musculoskeletal discomfort, musculoskeletal pain, musculoskeletal strain, neck pain, participatory ergonomics, shoulder pain, randomized controlled trial, workload.

The use of graphics software and nonkeyboard input devices (eg, the mouse) has increased rapidly and created new demands for the design of office workplaces. In the European Union $40 \%$ of the workforce used computers for more than a fourth of their worktime in 1996 (1). The number of computer users has increased enormously since then.

Postural stress caused by poor workstation ergonomics, number of hours of computer usage, and high work demands have been associated with a variety of musculoskeletal and visual problems. Redesign, ergonomic improvements, and education have generally been recommended as solutions for the prevention of musculoskeletal disorders in work with a video display unit (VDU) (2-5). A limited number of well-designed intervention studies with reference groups has been published to evaluate the effectiveness of ergonomic intervention in the office environment $(4,6-8)$. There is some evidence that keyboard and mouse users may experience a reduction in upper-extremity and neck pain when using certain alternative keyboards or types of mouse than when using conventional ones (9-11). A training program in ergonomics (12), workstation adjustment (5, 13-15), and frequent breaks in VDU work (16) have been shown to decrease the prevalence of musculoskeletal disorders and discomfort. However, only a few of these latter studies have followed the standards for reporting randomized controlled trials (17).

We carried out a randomized controlled trial on the effects of physical ergonomics on musculoskeletal symptoms in VDU work. We studied the effects of an intensive participatory ergonomic approach and

1 Finnish Institute of Occupational Health, Topeliuksenkatu 41 a A, FIN-00250 Helsinki, Finland.

2 The Expert Group in Ergonomics: Helena Hanhinen of Espoo City, Espoo, Finland, and Ritva Kukkonen, Ella Kylmäaho, MSc, and Sirpa Rauas of the Finnish Insitute of Occupational Health, Helsinki, Finland.

Reprint requests to: Ritva Ketola, Finnish Institute of Occupational Health, Topeliuksenkatu 41 a A, FIN-00250 Helsinki, Finland. [E-mail: ritva.ketola@ttl.fi] 
education on the level of musculoskeletal discomfort and strain and also on the prevalence of pain.

\section{Subjects and methods}

\section{Design}

The study was carried out during 1998-1999 in three administrational units of a medium-sized city in Finland. Employees working with a VDU in the office for more than 4 hours a week $(\mathrm{N}=515)$ were asked to fill out a questionnaire. Questions on musculoskeletal pain and strain, general health, work environment factors, time working with a VDU and input devices, types of software, and work organizational and psychosocial factors were inquired about. One hundred and twenty-four subjects with musculoskeletal symptoms were selected and randomly allocated into three intervention groups. Data on workplace layout and dimensions were collected before the intervention and also 2 and 10 months after it by two experts in ergonomics. They were blinded to the group assignment of the study subjects. The outcome measure was musculoskeletal discomfort as recorded in a diary kept for 2 weeks during the 2- and 10-month follow-ups. In addition, pain and strain symptoms were inquired about in a questionnaire 12 months after the preliminary survey (ie, about 7-10 months after the intervention) (figure 1).

\section{Subjects}

The baseline questionnaire was returned by 416 employees (222 women, 194 men) of the study base $(\mathrm{N}=515)$. The employees were mainly secretaries, technicians, architects, engineers, or draftspersons.

The study population for the interventions was selected on the basis of reported musculoskeletal symptoms, mouse usage, and age with the following criteria:

- symptoms in the neck, shoulders, or upper-limb region in at least one and, at most, eight anatomical areas (out of 11 areas illustrated by a manikin in the questionnaire) during the preceding month (30 days): the aim was to recruit subjects who had only a moderate number of symptoms and might therefore benefit most from the ergonomic intervention (6 subjects were excluded due to too many symptoms);

- mouse used for more than $5 \%$ of the worktime with a VDU;

- age $<61$ years.

The subjects fulfilling the inclusion criteria $(\mathrm{N}=124)$ were allocated into three groups (intensive ergonomics, education in ergonomics, reference) using stratified random sampling. The three administrational units were used as a stratum. The success of the randomization was checked with regard to age, gender, VDU worktime, mouse usage, and symptoms in the neck. Table 1 describes the characteristics of the groups.

The subjects were given written information on the aims and the contents of the study before they signed

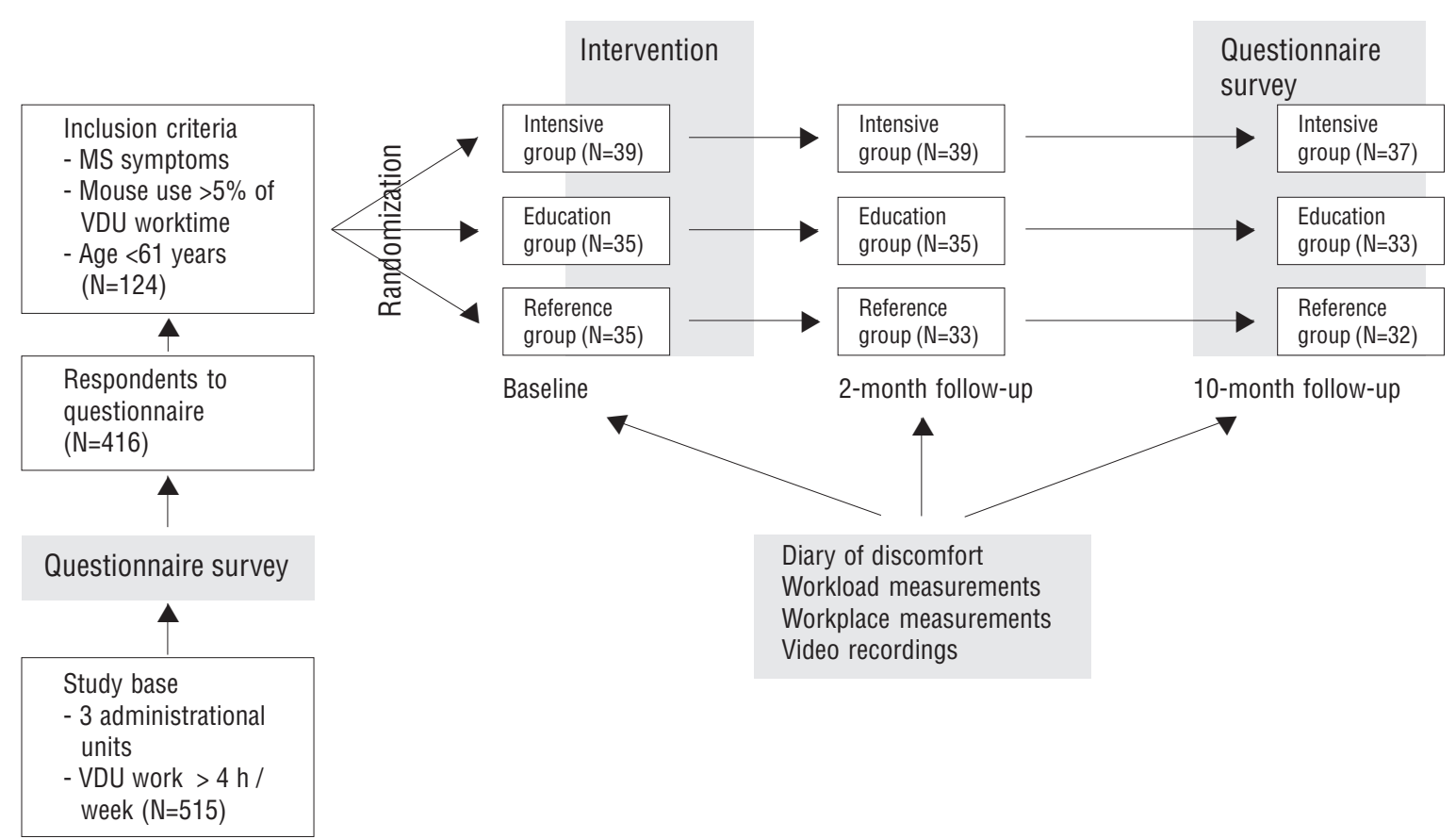

Figure 1. Study design. (MS = musculoskeletal, VDU = video display unit) 
Table 1. Characteristics of the study subjects at the beginning of the study. (VDU = video display unit)

\begin{tabular}{|c|c|c|c|c|c|c|c|c|c|c|c|c|c|c|c|c|c|c|}
\hline \multirow[t]{2}{*}{ Group } & \multirow[t]{2}{*}{$\begin{array}{c}\text { Wom- } \\
\text { en } \\
(\%)\end{array}$} & \multirow[t]{2}{*}{$\begin{array}{l}\text { Men } \\
(\%)\end{array}$} & \multicolumn{2}{|c|}{$\begin{array}{l}\text { Preva- } \\
\text { lence } \\
\text { of pain } \\
(\%)\end{array}$} & \multicolumn{3}{|c|}{$\begin{array}{l}\text { Dominant hand } \\
(\%)\end{array}$} & \multicolumn{2}{|c|}{$\begin{array}{c}\text { Age } \\
\text { (years) }\end{array}$} & $\begin{array}{l}\text { Height } \\
(\mathrm{cm})\end{array}$ & \multicolumn{2}{|c|}{$\begin{array}{l}\text { Body weight } \\
\qquad(\mathrm{kg})\end{array}$} & \multicolumn{2}{|c|}{$\begin{array}{l}\text { Work } \\
\text { experience } \\
\text { (years) }\end{array}$} & \multicolumn{2}{|c|}{$\begin{array}{l}\text { VDU work } \\
\text { (\% of total } \\
\text { work time) }\end{array}$} & \multicolumn{2}{|c|}{$\begin{array}{l}\text { Mouse use } \\
\text { ( } \% \text { of total } \\
\text { work time) }\end{array}$} \\
\hline & & & $\begin{array}{l}\text { Neck } \\
\text { (local) }\end{array}$ & $\begin{array}{l}\text { Neck } \\
\text { (radi- } \\
\text { ating) }\end{array}$ & Right & Left & $\begin{array}{l}\text { Ambi- } \\
\text { dex- } \\
\text { trous }\end{array}$ & Mean & Range & Mean Range & Mean & Range & Mean & Range & Mean & Range & Mean & Range \\
\hline $\begin{array}{l}\text { Intensive } \\
(\mathrm{N}=39)\end{array}$ & 60 & 40 & 78 & 55 & 90 & 5 & 5 & 46 & $29-59$ & 170 158-190 & 73 & $48-110$ & 17 & $2-35$ & 44 & $5-90$ & 41 & 5-95 \\
\hline $\begin{array}{l}\text { Education } \\
(\mathrm{N}=35)\end{array}$ & 60 & 40 & 77 & 57 & 86 & 3 & 11 & 49 & $27-60$ & 169 150-192 & 71 & $47-102$ & 19 & $6-33$ & 46 & $5-80$ & 45 & $10-85$ \\
\hline $\begin{array}{l}\text { Reference } \\
(\mathrm{N}=35)\end{array}$ & 54 & 46 & 77 & 58 & 91 & 6 & 3 & 49 & $31-59$ & 169 152-194 & 72 & $46-135$ & 19 & $1-30$ & 44 & $10-90$ & 41 & $5-90$ \\
\hline
\end{tabular}

the consent form. Those in the reference group were told that, after the study period, they would be given the possibility to receive ergonomic advice similar to that given to the intensive group. The local ethics committee accepted the study protocol.

Nine subjects refused to participate in the study. Five had a long sick leave, and one subject had died. Thus, at the beginning of the study, there were 109 participants. In the 2-month follow-up there were 107 participants ( 1 changed workplaces and 1 had a long sick leave), and, in the 10-month follow-up, there were 102 subjects still remaining ( 3 changed workplaces and 2 had a long sick leave) (figure 1).

\section{Assessment of the level of ergonomics and workload}

At the beginning of the study, the two experts in ergonomics made video recordings of the subjects in their usual daily tasks; the recording was repeated 2 months and 10 months after the intervention. A continuous 4minute extract was chosen from the recordings of each subject at each study time point to represent the subject's most common VDU task. Two researchers, also blinded to the group status of the subjects, analyzed these extracts in random order. Both of them gave an overall ergonomic rating on a scale from 4 ("poor") to 10 ("excellent"), a scale used in the Finnish educational system. The mean of the ratings of the two researchers was used to describe the ergonomic level of each workstation. The interobserver repeatability of the rating had been tested before the study (Pearson's correlation coefficient $\mathrm{r}=0.85$ ).

During the 2-week period at baseline, when the worker filled in the diary, a special program (WorkPace $^{\mathrm{TM}}$, Niche Software Limited, New Zealand) was used to monitor keyboard and mouse usage continuously. Data were saved into a daily file containing the exact history of keyboard and mouse events with an accuracy of 10 milliseconds. For the assessment of daily workload, daily computer usage (in minutes) was calculated. Pauses longer than 2 minutes for keyboard use and longer than 30 seconds for mouse use were excluded from the calculation. Due to technical problems, this recording was successfully completed for 56 subjects only (19 in the intensive ergonomics, 21 in the education, and 16 in the reference groups).

\section{Health outcomes}

The participants were asked to keep a diary on comfort three times per workday: at the start of the workday, at noon, and at the end of the workday. The diary consisted of questions on discomfort in different anatomical areas. (See table 4 in the Results section.) The rating of discomfort had five levels ranging from 1 "feel good" to 5 "feel very uncomfortable". A manikin (modified Nordic questionnaire) was used to define the anatomical areas (18). The subjects kept the diary for 2 weeks before the intervention, and for 2 weeks during the 2month and 10-month follow-ups.

The baseline and the follow-up questionnaires included questions on musculoskeletal strain and pain. Strain after the usual workday during the preceding month (30 days) was assessed by a five-level scale ranging from 1 "no strain at all" to 5 "very much strain". The questions on pain during the preceding month (30 days) addressed the number of days with pain, and the responses were classified into "no pain" ( 0 day) and "pain" ( $\geq 1$ days).

\section{Interventions}

A one-page leaflet on musculoskeletal health in association with VDU work was given to each subject on the day of the baseline measurements. Similar general information is available in daily newspapers.

Intensive ergonomics. Two physiotherapists visited the worksite of every member of the intensive ergonomics group. First, they introduced an ergonomic checklist for VDU work (see http://www.occuphealth.fi/ergonomia/ checklist.html) to the subject. The checklist emphasized the following three items: the layout and environmental 
conditions of the workroom (4 questions), adjustments of the workstation (7 questions), and breaks during work (1 question). The subjects independently assessed their workstations with the aid of the list and answered the questions. If they found any need for improvement, they wrote down their suggestions. Potential ergonomic improvements based on the workers' own views, as well as on the physiotherapists' observations, were then discussed. First adjustments and alterations in the existing furniture and work equipment were used in an attempt to reach the best solution. The worker was encouraged to participate actively in the redesign and rearrangement of his or her workstation. New forearm and wrist rests were readily available if needed. For 11 workstations, the acquisition of a new piece of furniture (desk, chair, etc) was suggested. The workers were also advised to pay attention to their work postures and to add short pauses into their work. The ergonomic evaluation and the implementation of the immediate changes for a workstation took approximately 1.5-2 hours. Two of 39 workstations remained unchanged because the workers seemed to be reluctant to make any changes.

Ergonomic education. The workers attended a 1-hour training session in ergonomics in groups of 2 to 6 persons. A trainer in ergonomics instructed the workers concerning the principles of ergonomics in VDU work. They received the same checklist as the intensive group members and were encouraged to evaluate their own workstation, implement changes, and ask for new equipment and furniture if needed. Moreover, the workers were instructed to add short pauses and adopt relaxed work postures. All the subjects in the education group attended the training session.

Reference. The one-page leaflet was the only intervention given the reference group, in addition to measurements similar to those of the other groups.

\section{Ergonomic consultations with an occupational physiotherapist}

The workers had their occupational health services, including preventive health care, in a nearby occupational health unit of the city. An occupational physiotherapist was available for problems in ergonomics. Ergonomic consultations were recorded during the followup period.

\section{Statistical analysis}

A one-way analysis of variance was used to test for differences in the ergonomic ratings between the three groups. Each time point was handled separately. In the cases in which the F-test was statistically significant, we applied the unpaired t-test for comparisons between two groups (intensive versus reference and education versus reference). A 5\% level was considered to be statistically significant.

Musculoskeletal strain and maximal discomfort from the follow-up questionnaire and diary were kept as continuous outcome variables when the analysis of covariance was applied. The baseline value of the outcome variable, the initial ergonomic rating, and the baseline workload value (keyboard and mouse events) were included in the models as covariates. Due to missing data on workload, this modeling was carried out also without workload. The adjusted means of the outcomes and their standard errors were calculated, and the one-sided Dunnett's test was used to determine statistical significances between the differences in the adjusted means of the groups (19). The two intervention groups were contrasted against the reference group.

Musculoskeletal pain from the 10-month questionnaire was handled as a binary variable, and logistic regression models were applied to assess the association between the pain and type of intervention. The baseline value of the outcome variable was used as a confounder in these models.

\section{Results}

\section{Changes in workstation ergonomics}

Table 2 lists the most common changes in the workstations observed or measured by two blinded experts. Changes in screen height or keyboard height or the acquisition of accessories (ie, wrist and forearm support) occurred typically in the intensive ergonomics group, whereas adjustments of chair or mouse location were made in all the groups. It should be noted that the data in table 2 do not contain information on whether the changes were beneficial or not.

\section{Ratings of workstation ergonomics}

The means of the ergonomic ratings did not differ between the groups at the beginning of the study. At the time of the 2- and 10-month follow-ups the ergonomic level was rated significantly higher in the intensive group than in the education or reference group (table 3 ). The interobserver repeatability of the rating was 0.78 (Pearson's correlation coefficient).

\section{Daily ratings of discomfort}

In the 2-month follow-up the intensive group had less discomfort than the reference group in the neck, in the area between the neck and shoulder on the right side, in the right and left shoulder, in the fingers of the left hand, 
and in the upper back (adjustment for the baseline measurements of musculoskeletal discomfort and initial ergonomic rating). As compared with the workers in the reference group, the education group had less discomfort in the neck, in the area between the neck and shoulder on the right side, in the right forearm, and in the

Table 2. Changes in the workstation dimensions or accessories in use at the 10-month follow-up.

\begin{tabular}{lccc}
\hline Type of change & $\begin{array}{c}\text { Intensive } \\
\text { group } \\
(\mathrm{N}=37) \\
(\%)\end{array}$ & $\begin{array}{c}\text { Education } \\
\text { group } \\
(\mathrm{N}=35) \\
(\%)\end{array}$ & $\begin{array}{c}\text { Reference } \\
\text { group } \\
(\mathrm{N}=32) \\
(\%)\end{array}$ \\
\hline Screen height & 78 & 29 & 56 \\
Keyboard desk height & 78 & 26 & 47 \\
Chair adjustment & 62 & 57 & 41 \\
Mouse location & 49 & 37 & 31 \\
Wrist support acquisition & 49 & 14 & 3 \\
Forearm support acquisition & 24 & 0 & 0 \\
\hline
\end{tabular}

upper back. The results showed the same trend at the 10-month follow-up even though there were no significant differences between the groups (table 4).

When additional adjustment was made for workload ( $\mathrm{N}=56) 2$ months after the intervention, the intensive group had less discomfort than the reference group in the neck, in the area between the neck and shoulder on both sides, in the right and left shoulders, in the fingers of the left hand, and in the upper back. The education group also had less discomfort in the neck, in the area between the neck and shoulder on both sides, in the shoulders on both sides, and in the upper back. The results showed the same trend in the 10-month follow-up even though there were no significant differences between the groups.

\section{Musculoskeletal strain and pain}

In the 10-month follow-up the intensive group showed a tendency towards less strain than in the education or

Table 3. Ratings of workstation ergonomics (workstation settings and postural stressors) before the intervention and in the 2- and 10month follow-up (scale from 4 to 10).

\begin{tabular}{|c|c|c|c|c|c|c|c|c|c|c|c|}
\hline \multirow[t]{2}{*}{ Group } & \multicolumn{3}{|c|}{ Before intervention } & \multicolumn{4}{|c|}{ 2-month follow-up } & \multicolumn{4}{|c|}{ 10-month follow-up } \\
\hline & $\mathrm{N}$ & Mean & $\mathrm{SD}$ & $N$ & Mean & SD & P-value & $\mathrm{N}$ & Mean & $\mathrm{SD}$ & P-value \\
\hline Intensive & 39 & 6.7 & 0.2 & 39 & 7.7 & 0.2 & $0.001^{a}$ & 37 & 8.0 & 0.1 & $0.002^{a}$ \\
\hline Education & 35 & 6.8 & 0.2 & 35 & 6.7 & 0.2 & $0.73^{b}$ & 33 & 7.1 & 0.2 & $0.60^{b}$ \\
\hline Reference & 35 & 6.7 & 0.2 & 33 & 6.8 & 0.2 & . & 32 & 7.3 & 0.2 & . \\
\hline
\end{tabular}

a Unpaired t-test between intensive and reference group.

b Unpaired t-test between education and reference group.

Table 4. Musculoskeletal discomfort in the 2- and 10-month follow-ups (adjusted for the baseline value of discomfort and expert rating of ergonomics) ( $\mathrm{N}=85)$. ( $\mathrm{SE}=$ standard error of the least square means)

\begin{tabular}{|c|c|c|c|c|c|c|c|c|c|c|c|c|c|c|c|c|}
\hline \multirow[t]{3}{*}{ Body area } & \multicolumn{8}{|c|}{ 2-month follow-up } & \multicolumn{8}{|c|}{ 10-month follow-up } \\
\hline & \multicolumn{3}{|c|}{$\begin{array}{l}\text { Intensive group } \\
\quad(\mathrm{N}=28)\end{array}$} & \multicolumn{3}{|c|}{$\begin{array}{l}\text { Education group } \\
\qquad(\mathrm{N}=31)\end{array}$} & \multicolumn{2}{|c|}{$\begin{array}{l}\text { Reference group } \\
\qquad(\mathrm{N}=26)\end{array}$} & \multicolumn{3}{|c|}{$\begin{array}{l}\text { Intensive group } \\
\quad(\mathrm{N}=28)\end{array}$} & \multicolumn{3}{|c|}{$\begin{array}{l}\text { Education group } \\
\qquad(\mathrm{N}=31)\end{array}$} & \multicolumn{2}{|c|}{$\begin{array}{l}\text { Reference group } \\
\qquad(\mathrm{N}=26)\end{array}$} \\
\hline & Mean & SE & P-value a & Mean & SE & $\mathrm{P}$-value ${ }^{\mathrm{b}}$ & b Mean & SE & Mean & SE & P-value a & Mean & SE P & P-value ${ }^{b}$ & Mean & SE \\
\hline Head & 2.5 & 0.2 & 0.088 & 2.7 & 0.2 & 0.30 & 3.0 & 0.2 & 2.7 & 0.2 & 0.13 & 2.8 & 0.2 & 0.26 & 3.0 & 0.2 \\
\hline Eyes & 2.6 & 0.2 & 0.24 & 2.8 & 0.2 & 0.54 & 2.9 & 0.2 & 3.0 & 0.2 & 0.38 & 3.1 & 0.2 & 0.49 & 3.2 & 0.2 \\
\hline Neck & 2.7 & 0.2 & 0.014 & 2.7 & 0.1 & 0.013 & 3.3 & 0.2 & 2.9 & 0.2 & 0.24 & 3.0 & 0.1 & 0.30 & 3.2 & 0.2 \\
\hline $\begin{array}{l}\text { Area between neck and } \\
\text { shoulder (right) }\end{array}$ & 2.5 & 0.1 & 0.007 & 2.5 & 0.1 & 0.002 & 3.1 & 0.2 & 2.7 & 0.2 & 0.37 & 2.6 & 0.2 & 0.27 & 2.9 & 0.2 \\
\hline $\begin{array}{l}\text { Area between neck and } \\
\text { shoulder (left) }\end{array}$ & 2.3 & 0.2 & 0.17 & 2.3 & 0.1 & 0.11 & 2.6 & 0.2 & 2.6 & 0.2 & 0.69 & 2.6 & 0.2 & 0.65 & 2.6 & 0.2 \\
\hline Right shoulder & 2.2 & 0.2 & 0.022 & 2.4 & 0.1 & 0.12 & 2.8 & 0.2 & 2.6 & 0.2 & 0.53 & 2.5 & 0.2 & 0.36 & 2.7 & 0.2 \\
\hline Left shoulder & 1.9 & 0.1 & 0.025 & 2.1 & 0.1 & 0.15 & 2.4 & 0.2 & 2.2 & 0.2 & 0.61 & 2.4 & 0.2 & 0.86 & 2.3 & 0.2 \\
\hline Right forearm & 2.1 & 0.1 & 0.077 & 2.0 & 0.1 & 0.009 & 2.5 & 0.2 & 2.3 & 0.2 & 0.36 & 2.1 & 0.2 & 0.14 & 2.5 & 0.2 \\
\hline Left forearm & 1.9 & 0.1 & 0.57 & 1.9 & 0.1 & 0.59 & 2.0 & 0.1 & 2.1 & 0.2 & 0.56 & 2.0 & 0.2 & 0.48 & 2.2 & 0.2 \\
\hline Right wrist & 2.1 & 0.2 & 0.13 & 2.0 & 0.2 & 0.062 & 2.4 & 0.2 & 2.5 & 0.2 & 0.87 & 2.1 & 0.2 & 0.31 & 2.3 & 0.2 \\
\hline Left wrist & 1.9 & 0.1 & 0.19 & 1.9 & 0.1 & 0.26 & 2.1 & 0.1 & 2.1 & 0.2 & 0.86 & 2.1 & 0.2 & 0.86 & 2.0 & 0.2 \\
\hline Right fingers & 1.9 & 0.1 & 0.075 & 2.1 & 0.1 & 0.38 & 2.3 & 0.1 & 2.1 & 0.2 & 0.31 & 2.2 & 0.2 & 0.35 & 2.3 & 0.2 \\
\hline Left fingers & 1.8 & 0.1 & 0.017 & 1.9 & 0.1 & 0.092 & 2.3 & 0.1 & 2.1 & 0.2 & 0.72 & 2.1 & 0.2 & 0.73 & 2.1 & 0.2 \\
\hline Upper back & 2.2 & 0.1 & 0.001 & 2.4 & 0.1 & 0.005 & 2.9 & 0.1 & 2.6 & 0.2 & 0.24 & 2.5 & 0.2 & 0.17 & 2.9 & 0.2 \\
\hline Low back & 2.3 & 0.2 & 0.13 & 2.5 & 0.2 & 0.40 & 2.7 & 0.2 & 2.5 & 0.2 & 0.55 & 2.7 & 0.2 & 0.75 & 2.6 & 0.2 \\
\hline
\end{tabular}

a One-sided Dunnett's test between the intensive and reference groups.

${ }^{b}$ One-sided Dunnett's test between the education and reference groups. 
reference groups during the preceding 30 days in 12 anatomical areas after adjustment for the baseline values of musculoskeletal strain (questionnaire) and the ergonomic ratings. No significant differences were found between the groups. Nor were there differences in the prevalence of musculoskeletal pain during the preceding 30 days.

\section{Consultations with the occupational physiotherapist}

Ten subjects in the intensive group, seven in the education group, and eight in the reference group contacted the occupational physiotherapist to get ergonomic advice during the 10 months of follow-up.

\section{Discussion}

This study investigated the efficacy of the participatory ergonomic approach and education on musculoskeletal discomfort and strain, as well as on the prevalence of pain in VDU work. The intensive and the education groups showed less musculoskeletal discomfort than the reference group in the 2-month follow-up. However, long-term effects on discomfort, strain, or pain were not found in the 10-month follow-up. After the intervention the level of ergonomics, rated by two researchers, was distinctly higher in the intensive ergonomics group than in the education or reference group. Furthermore, most changes in the workstation dimensions and accessories occurred in the intensive ergonomics group. This occurrence suggests that the changes made to workstations had a positive impact on their ergonomic conditions.

The workstation modifications mainly included adjustments of the screen, mouse, keyboard, forearm supports, and chair. These modifications changed the head, neck, and arm postures and movements. Since the positive effects were seen primarily in the shoulder, upper arm, neck, and upper back area, it is possible that the health effects were brought about by these changes.

The strength of our study was that all three groups were comparable as regards demographic characteristics and occupational factors measured at the beginning of the study. The subjects were chosen for the three groups by individual randomization using the administrative unit as the stratum. Hence cultural differences between the units were controlled for. On the other hand, it was practically impossible to prevent personal interaction between the groups. The changes in the workstation dimensions, and the slight ergonomic improvement in the reference group may have been due to such interaction between the reference group and the intensive or education group or simply the result of a continuous development of the workplaces. The observed effect of the intervention may therefore be an underestimation of the true effect.

Moreover, technical problems, resulting in a loss of workload data for a third of the subjects, may have weakened the power of our analysis. The loss of measurements was, however, evenly distributed between the groups.

On the average, the prevalence of pain and the baseline values of the strain ratings were relatively low. Therefore, it is not surprising that no major effects were seen in this study. Nevertheless, the intervention decreased discomfort and therefore indicated that the sensation of discomfort is more reversible than pain or strain. It is a common hypothesis, as yet unproved, that discomfort and strain are predecessors of pain.

In a controlled intervention study, Brisson et al (12) found an ergonomic training program to be an effective tool in improving the ergonomics of VDU workers' workstations. The intervention of Menozzi et al (20) also showed training to be useful in optimizing ergonomics in VDU work. In our study the ergonomic level did not differ between the education and reference groups. It may be that the short 1-hour training session was not efficient enough to activate workers to improve their workstation ergonomics. Furthermore, workers may need concrete help and guidance to plan and implement changes in their workstations.

Although there were only some improvements in the ergonomic level of the education group, this group reported less discomfort than the reference group. It may be that the workers adopted a better work technique or had found other ways to improve the organization of their work or they added more pauses to their work. Frequent short breaks from VDU work have been shown to reduce musculoskeletal discomfort and other complaints (16).

Mekhora \& Liston (14) modified VDU workstations to comply with the dimensions calculated by a computer application based on the anthropometry of the workers. The authors concluded that changes in workstation dimensions could help to reduce the discomfort level of the participants by changing the work postures. Gerr (21) found, however, that work postures are not greatly affected by workstation dimensions. He pointed out that many computer users do not work in so-called neutral postures. People, while sitting, use a range of different postures. Feelings of discomfort or fatigue also modify the sitting posture. Good workstation design supports a beneficial posture and the variety of postures during VDU work. In our study, we utilized a participatory approach and personal guidance in order to take into account the individual preferences of workers and changes in worktasks.

Our study concentrated only on physical ergonomics. In order to make ergonomic intervention more 
effective, psychosocial and organizational workplace factors also deserve greater attention $(4,22)$.

Our results showed that both an intensive ergonomics approach and education in ergonomics help reduce discomfort in VDU work. To improve the level of physical ergonomics in VDU workplaces, the best result will be achieved by cooperative planning in which both workers and practitioners are actively involved.

\section{Acknowledgments}

We would like to thank the occupational health and safety staff of the city of Espoo.

Financial support was provided by the Finnish Work Environment Fund.

\section{References}

1. Paoli P. Second European survey on working conditions in the European Union. Dublin: European Foundation for the Improvement of Living and Working Conditions. 1997.

2. Moon SD, Sauter SL, editors. Beyond biomechanics: psychosocial aspects of musculoskeletal disorders in office work. London: Taylor \& Francis; 1996.

3. Karlqvist L, Hagberg M, Köster M, Wenemark M, Ånell R. Musculoskeletal symptoms among computer-assisted design (CAD) operators and evaluation of a self-assessment questionnaire. Int J Arch Environ Health 1996;2:185-94.

4. Fernström E. Physical load in computerised office work with special reference to work tasks and equipment. Stockholm: Royal Institute of Technology, 1997.

5. Bayeh A, Smith M. Effect of physical ergonomics on VDT workers' health: a longitudinal intervention field study in a service organization. Int J Hum Comput Interaction 1999; 11(2):109-35.

6. Punnett L. Visual display unit work and upper extremity musculoskeletal disorders. Solna: Arbetslivsinstitutet, 1997. Arbete och hälsa 1997;16.

7. Aarås A, Horgen G, Ro O. Work with the visual display unit: health consequences. Int J Hum Comput Interaction 2000; 12(1):107-34.

8. Westgaard RH, Winkel J. Ergonomic intervention research for improved musculoskeletal health: a critical review. Int J
Ind Ergon 1997;20(6):463-500.

9. Tittiranonda P, Rempel D, Armstrong T, Burastero S. Effect of four computer keyboards in computer users with upper extremity musculoskeletal disorders. Am J Ind Med 1999;35(6):647-61.

10. Rempel D, Tittiranonda P, Burastero S, Hudes M, So Y. Effect of keyboard keyswitch design on hand pain. J Occup Environ Med 1999;41(2):111-9.

11. Aarås $\mathrm{A}, \mathrm{Ro} \mathrm{O}$, Thoresen $\mathrm{M}$. Can a more neutral position of the forearm when operating a computer mouse reduce the pain level for visual display unit operators? A prospective epidemiological intervention study. Int J Hum Comput Interaction 1999;11(2):79-94.

12. Brisson C, Montreuil S, Punnett L. Effects of an ergonomic training program on workers with video display units. Scand J Work Environ Health 1999;25(3):255-63.

13. Aarås A. Relationship between trapezius load and the incidence of musculoskeletal illness in the neck and shoulder. Int J Ind Ergon 1994;14:341-348.

14. Mekhora K, Liston $\mathrm{C}$. The effect of ergonomic intervention on discomfort in computer users with tension neck syndrome. Int J Ind Ergon 2000;26(3):367-79.

15. Kamwendo K, Linton S. A controlled study of the effect of neck school in medical secretaries. Scand J Rehabil Med 1991;23:143-52.

16. Henning R, Jacques P, Kissel G, Sullivan A, Alteras-Webb S. Frequent short rest breaks from computer work: effects on productivity and well-being at two field sites. Ergonomics 1997;40(1):78-91.

17. Begg C, Cho M, Eastwood S, Horton R, Moher D, Olkin I, et al. Improving the quality of reporting of randomized controlled trials. JAMA 1996;276(8):637-9.

18. Kuorinka I, Jonsson B, Kilbom ^, Vinterberg H, BieringSørensen F: Standardised Nordic questionnaires for the analysis of musculoskeletal symptoms. Appl Ergon 1987;18:2337.

19. SAS Institute Inc. SAS/STAT® user's guide; version 8. Cary (NC): SAS Institute Inc, 1999.

20. Menozzi M, Waldmann H, Kundig S, Krueger H, Spieler W. Training in ergonomics at VDU workplaces. Ergonomics 1999;42(6):835-45.

21. Gerr F, Marcus M, Ortiz D, White B, Jones W, Cohen S, et al. Computer users' postures and associations with workstation characteristics. Am Ind Hyg Assoc J 2000;61(2):223-30.

22. Bergqvist U, Wolgast E, Nilsson B, Voss M. Muskuloskeletal disorders among, visual display terminal workers: individual, ergonomics, and work organizational factors. Ergonomics 1995;38(4):763-76.

Received for publication: 7 May 2001 